\title{
Integrating laboratory and field data to quantify the immersion freezing ice nucleation activity of mineral dust particles
}

\author{
P. J. DeMott ${ }^{1}$, A. J. Prenni ${ }^{1,}$, G. R. McMeeking ${ }^{2}$, R. C. Sullivan ${ }^{3}$, M. D. Petters ${ }^{4}$, Y. Tobo ${ }^{1, * *}$, M. Niemand ${ }^{5}$, \\ O. Möhler ${ }^{5}$, J. R. Snider ${ }^{6}$, Z. Wang ${ }^{6}$, and S. M. Kreidenweis ${ }^{1}$ \\ ${ }^{1}$ Department of Atmospheric Science, Colorado State University, Fort Collins, CO 80523-1371, USA \\ ${ }^{2}$ Droplet Measurement Technologies, Boulder, CO, USA \\ ${ }^{3}$ Center for Atmospheric Particle Studies, Carnegie Mellon University, Pittsburgh, PA, USA \\ ${ }^{4}$ Department of Marine, Earth and Atmospheric Sciences, North Carolina State University, Raleigh, NC, USA \\ ${ }^{5}$ Institute for Meteorology and Climate Research - Atmospheric Aerosol Research, Karlsruhe Institute of Technology, \\ Karlsruhe, Germany \\ ${ }^{6}$ Department of Atmospheric Sciences, University of Wyoming, Laramie, WY, USA \\ *now at: Air Resources Division, National Park Service, Denver, CO, USA \\ ** now at: National Institute of Polar Research, Tachikawa, Tokyo 190-8518, Japan
}

Correspondence to: P. J. DeMott (paul.demott@ colostate.edu)

Received: 9 June 2014 - Published in Atmos. Chem. Phys. Discuss.: 27 June 2014

Revised: 5 October 2014 - Accepted: 1 December 2014 - Published: 13 January 2015

\begin{abstract}
Data from both laboratory studies and atmospheric measurements are used to develop an empirical parameterization for the immersion freezing activity of natural mineral dust particles. Measurements made with the Colorado State University (CSU) continuous flow diffusion chamber (CFDC) when processing mineral dust aerosols at a nominal $105 \%$ relative humidity with respect to water $\left(\mathrm{RH}_{\mathrm{w}}\right)$ are taken as a measure of the immersion freezing nucleation activity of particles. Ice active frozen fractions vs. temperature for dusts representative of Saharan and Asian desert sources were consistent with similar measurements in atmospheric dust plumes for a limited set of comparisons available. The parameterization developed follows the form of one suggested previously for atmospheric particles of nonspecific composition in quantifying ice nucleating particle concentrations as functions of temperature and the total number concentration of particles larger than $0.5 \mu \mathrm{m}$ diameter. Such an approach does not explicitly account for surface area and time dependencies for ice nucleation, but sufficiently encapsulates the activation properties for potential use in regional and global modeling simulations, and possible application in developing remote sensing retrievals for ice nucleating particles. A calibration factor is introduced to account for the apparent underestimate (by approximately 3 , on aver-
\end{abstract}

age) of the immersion freezing fraction of mineral dust particles for CSU CFDC data processed at an $\mathrm{RH}_{\mathrm{w}}$ of $105 \% \mathrm{vs}$. maximum fractions active at higher $\mathrm{RH}_{\mathrm{w}}$. Instrumental factors that affect activation behavior vs. $\mathrm{RH}_{\mathrm{w}}$ in CFDC instruments remain to be fully explored in future studies. Nevertheless, the use of this calibration factor is supported by comparison to ice activation data obtained for the same aerosols from Aerosol Interactions and Dynamics of the Atmosphere (AIDA) expansion chamber cloud parcel experiments. Further comparison of the new parameterization, including calibration correction, to predictions of the immersion freezing surface active site density parameterization for mineral dust particles, developed separately from AIDA experimental data alone, shows excellent agreement for data collected in a descent through a Saharan aerosol layer. These studies support the utility of laboratory measurements to obtain atmospherically relevant data on the ice nucleation properties of dust and other particle types, and suggest the suitability of considering all mineral dust as a single type of ice nucleating particle as a useful first-order approximation in numerical modeling investigations. 


\section{Introduction}

Ice nucleation by atmospheric aerosols impacts the microphysical composition, radiative properties, and precipitation processes in clouds colder than $0^{\circ} \mathrm{C}$. Since the processes responsible for ice nucleation are not fully understood at the molecular level, and it has yet to be demonstrated that the full variety of surface property influences on ice nucleation by the many types of aerosols present in the atmosphere can be described by phenomenological models, there is need to simplify description of ice nucleation as understood through measurements. Even with an improved understanding of ice nucleation from a fundamental standpoint, there will remain a need for simplified schemes to describe ice nucleation in computationally intensive numerical models and for developing links between aerosol optical properties and ice nucleating particle concentration profiles using remote sensing measurements (Seifert et al., 2011).

Complete description of ice nucleation for ice nucleating particles (INPs), INP and INPs being terms we will adopt in this paper following Vali (2014), requires consideration of all relevant heterogeneous ice nucleation mechanisms. As defined by Vali (1985), these mechanisms involve either deposition of ice from the vapor phase (deposition nucleation) or freezing of a particle liquid phase in the bulk of cloud droplets (immersion freezing), during action as a CCN (condensation freezing), or after collision of a particle with the surface of a liquid droplet (contact freezing). The relative importance of different ice nucleation mechanisms will be affected by INP mixing state, and also the cloud formation conditions and the thermodynamic path followed by particles entering clouds. Thus, for example, particles reaching cold cloud regions through the base of warm-based cumulus clouds may have a high likelihood of being within supercooled droplets at the point of freezing, whereas those entering the base of an altocumulus cloud at below $-20^{\circ} \mathrm{C}$ may be available to act via deposition and condensation or immersion freezing. We consider that immersion freezing may be the most critical mechanism for quantifying ice nucleation in moderately supercooled clouds because most INPs reaching supercooled cloud conditions arrive having spent substantial time in clouds, and potentially serving as CCN by virtue of their sizes and/or compositions. Murray et al. (2012) summarize additional observational support for the relative major importance of immersion freezing nucleation.

Data for developing simplified descriptions, or parameterizations, of INP concentrations may come exclusively from laboratory data (e.g., Niemand et al., 2012) or exclusively from field data (Tobo et al., 2013), or may combine laboratory and field data to test or constrain parameterization frameworks (Phillips et al., 2008, 2013; Niemand et al., 2012). Situations can occur for which a certain particle type dominates INPs during field measurements, and this offers the opportunity to investigate the consistency of laboratory and field measurements for the particular type of INP, and to thereby develop more representative parameterizations. This study emphasizes quantifying immersion freezing nucleation using laboratory and field measurements made with the Colorado State University (CSU) continuous flow diffusion chamber (CFDC) ice nucleation instrument. This instrument, described in detail by Rogers (1988) and Rogers et al. (2001), is designed to focus a flowing stream of particles in a narrow lamina within the water vapor and temperature gradient fields created between two cylindrical ice surfaces held at different temperatures in order to expose the particles to well-defined temperature and relative humidity conditions that promote ice nucleation. We will herein equate freezing nucleation occurring when operating the CFDC in the substantially supersaturated regime with respect to liquid water to immersion freezing since processing particles in this manner favors rapid formation of droplets prior to subsequent freezing (see next section). Recent studies for which CFDC measurements were made together with instruments or methods that mimic the immersion freezing process more explicitly support this assumption (Sullivan et al., 2010a; Niedermeier et al., 2011a; Garcia et al., 2012; Wex et al., 2014).

DeMott et al. (2010) applied similar considerations in developing a simplified parameterization of INP number concentrations of all compositional types intended for global model use on the basis of field data collected in multiple campaigns using the CSU CFDC instrument. Interpreting CFDC data in a deterministic manner (see Appendix A), DeMott et al. (2010), hereafter D10, demonstrated that incorporating dependence of INP number concentrations on aerosol number concentrations larger than $0.5 \mu \mathrm{m}$ greatly improved predicted INP compared to including temperature dependence alone. It was acknowledged that additional aerosol compositional dependencies might explain some of the variance remaining in observed INP number concentrations vs. values predicted by the D10 parameterization. This contention is supported by the fact that Tobo et al. (2013) observed systematic errors of predicted (D10) vs. measured INP number concentration at a single forest site, which appeared to have been dominated by biological INPs. In the present study, we seek to follow the approach of D10 and Tobo et al. (2013), but apply it exclusively to data on mineral dust INPs collected in the laboratory and in field measurements where mineral dust particles dominated in the layers where aircraft CFDC observations of INP number concentration were made. In this way, comparison can be made to a method that utilized only laboratory data from testing of varied mineral dust particles in the Aerosol Interactions and Dynamics of the Atmosphere (AIDA) chamber for development of an ice nucleation parameterization (Niemand et al., 2012).

\section{Methods}

All laboratory data used in this paper were collected during sampling at the AIDA chamber in the ICIS-2007 (Inter- 
national workshop on Comparing Ice nucleation measuring Systems - 2007) campaign (DeMott et al., 2011) and the ACI-03 (3rd Aerosol-Cloud Interaction) campaign, held in 2009. In these campaigns, multiple instruments sampled particles from a $4 \mathrm{~m}^{3}$ aerosol chamber, and sometimes from the larger $\left(84 \mathrm{~m}^{3}\right)$ AIDA chamber prior to cloud-forming expansions. Field study data are used from the Pacific Dust Experiment (PACDEX) (Stith et al., 2009) flown over the Pacific Ocean basin on the NSF/NCAR G-V aircraft in 2007, and the 2011 Ice in Clouds Experiment - Tropical (ICE-T) flown on the NSF/NCAR C-130 aircraft from St. Croix, US Virgin Islands (Heymsfield and Willis, 2014). The former study focused on Asian dust transports in the mid- to upper troposphere, while the latter study emphasized the influence of the Saharan aerosol layer on ice formation in tropical cumuli. The use of these data in this study is described in this section.

\subsection{Use and interpretation of CFDC data}

As done in D10, INP number concentrations active during the CFDC residence time for periods of stable conditions of the processing temperature in kelvin $\left(T_{\mathrm{k}}\right)$, relative humidity with respect to water $\left(\mathrm{RH}_{\mathrm{w}}\right)$, and pressure were tabulated as a function of aerosol particle concentrations for particles with diameters $>0.5 \mu \mathrm{m}$. Also as in D10, CFDC data were considered as deterministic outcomes rather than reflecting time-dependent nucleation rates. A brief discussion of this assumption, its possible validity, and implications are given in Appendix A. Data were stratified at $5^{\circ} \mathrm{C}$ temperature intervals, with a $1^{\circ} \mathrm{C}$ difference allowed about the target value. Finally, a reference condition was placed on the processing $\mathrm{RH}_{\mathrm{w}}$ deemed representative of immersion freezing nucleation. To explain the reason for and choice of a reference value, it is necessary to briefly review the CFDC principles of operation described in detail in other publications (e.g., Rogers, 1988; Rogers et al., 2001).

Aerosol enters the CFDC starting from ambient temperature conditions, but reduced to temperatures already below $273 \mathrm{~K}$ during entry into the insulated CFDC inlet manifold and with relative humidity lowered already by passage through diffusion dryers (DeMott et al., 2009). The aerosol lamina, representing typically $15 \%$ of the total flow, passes downward between sheath flows in the vertically oriented, cylindrical CFDC. In Fig. 1, calculations made based on the model of Rogers (1988) and focused at the central position of the aerosol lamina show how the sample rapidly cools and adjusts $\mathrm{SS}_{\mathrm{w}}$ (i.e., $\mathrm{RH}_{\mathrm{w}}-100 \%$ ) over 1 to $3 \mathrm{~s}$ in the upper part of the vertical chamber. The nearly steady-state central lamina temperature, $-30{ }^{\circ} \mathrm{C}$ in Fig. 1 , is determined by the warm (outer) and cold (inner) wall ice surface temperatures. Cooling of a few tenths of a degree continues as the $\mathrm{SS}_{\mathrm{w}}$ rises from subsaturated conditions to $5 \%$ for the case shown in Fig. 1. Depending on temperature, particle phase state, and $\mathrm{CCN}$ activation properties, deposition nucleation may be possible or the particle will otherwise be immersed

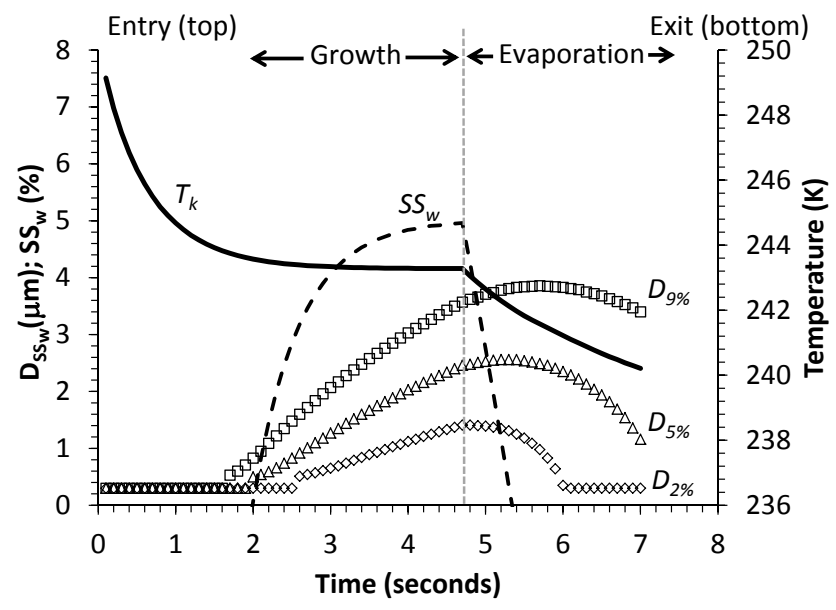

Figure 1. Calculated time-dependent temperature in kelvin $\left(T_{\mathrm{k}}\right)$, and supersaturation $\left(\mathrm{SS}_{\mathrm{W}}=\mathrm{RH}_{\mathrm{W}}-100 \%\right)$ for a potential INP starting at $0.3 \mu \mathrm{m}$ diameter and cooling to a target temperature of $-30^{\circ} \mathrm{C}$ and steady-state $\mathrm{SS}_{\mathrm{W}}$ of $\sim 5 \%$ in transit through the CFDC, using the model of Rogers (1988). Droplet diameter is shown for these calculated conditions $\left(D_{5} \%\right)$ and for conditions of $\mathrm{SS}_{\mathrm{W}}$ approaching $2 \%\left(D_{2} \%\right)$ and $9 \%\left(D_{9} \%\right)$ in the growth region prior to the point of transition into the ice-saturated (evaporation) region of the CFDC. Perfect water accommodation is assumed for these growth rate calculations. Flow rates specified are equivalent to those used in data collection for most samples used in this study, with a total residence time of $7 \mathrm{~s}$.

in a cloud droplet, favoring ice activation by condensation and immersion freezing, which we will assume not to distinguish here. The CSU CFDC design uses evaporation of liquid water droplets followed by optical particle sizing to differentiate activated INPs, grown to ice crystal sizes, from other aerosols. Evaporation is forced by the setting of equal (cold) ice wall temperatures in the lower $\sim 1 / 3$ of the CSU CFDC (Rogers et al., 2001; DeMott et al., 2010), or after about $4.7 \mathrm{~s}$ for the conditions in Fig. 1. Ice crystals survive the evaporation region, typically at sizes much larger than $3 \mu \mathrm{m}$ (not shown), used as the "cut-point" size separating ice vs. liquid in this study. Unfrozen liquid water droplets are reduced in size, at least until a certain steady-state supersaturation is exceeded in the upper growth section of the CFDC, whereupon droplets grow too large to shrink below the ice cut-point size in the time spent in the evaporation region. This high $\mathrm{RH}_{\mathrm{w}}$ limit has been referred to as the "droplet breakthrough" $\mathrm{RH}_{\mathrm{w}}$ (Stetzer et al., 2008). For the typical operational flow rate conditions used for the CSU CFDC, this is predicted to occur when $\mathrm{RH}_{\mathrm{w}}$ approaches $109 \%$ if a condensation coefficient of 1 is assumed for water growth and evaporation calculations when starting from the submicron (dry) sizes of particles typically generated for laboratory studies (Fig. 1). This will be a limitation specific to the geometry and flow rate of all continuous flow ice thermal diffusion chambers unless an explicit water/ice phase discrimination method is used for counting INPs. 


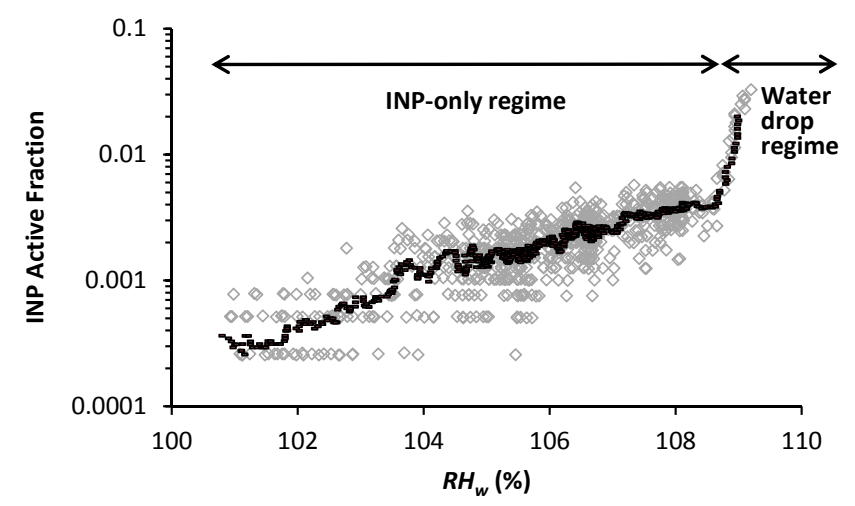

Figure 2. INP active fraction of mineral dust particles vs. $\mathrm{RH}_{\mathrm{W}}$ during a "scan" of $\mathrm{RH}_{\mathrm{w}}$ from low to high values during CFDC sampling from the AIDA chamber prior to a "first expansion" cloud formation experiment using a Saharan dust (type SD, AIDA experiment \#20, 25 September 2007) aerosol distribution with $n_{\mathrm{a}}=411 \mathrm{~cm}^{-3}, d_{\mathrm{g}}=0.18 \mu \mathrm{m}$, and $\sigma_{\mathrm{g}}=2.14$. A $15 \mathrm{~s}$ running mean line overlays $1 \mathrm{~Hz}$ data points. The regions of continuously increasing ice active fraction is distinguished from the region of onset of cloud droplet contamination of the ice signal above $108.5 \% \mathrm{RH}_{\mathrm{W}}$. Aerosol lamina temperature was maintained at $249.7 \mathrm{~K}$ during the scan.

Figure 2 confirms the reasonableness of the calculated upper $\mathrm{RH}_{\mathrm{w}}$ limitation for the CSU CFDC (Fig. 1), showing droplet breakthrough occurring at $108.5 \% \mathrm{RH}_{\mathrm{w}}$ while sampling mineral dust particles with a size mode at about $0.2 \mu \mathrm{m}$ and the size parameters stated in the caption of Fig. 2. The calculations in Fig. 1 are made for monodisperse $0.3 \mu \mathrm{m}$ particles. Droplet breakthrough is indicated in Fig. 2 by the point at which the apparent INP active fraction (i.e., $n_{\mathrm{INP}} / n_{\mathrm{a}}$, where $n_{\mathrm{a}}$ is total particle concentration measured with a condensation particle counter) rises sharply with further $\mathrm{RH}_{\mathrm{W}}$ increase. $\mathrm{RH}_{\mathrm{W}}$ values for this upper limit exceeding $110 \%$ have been observed in some other laboratory studies (Petters et al., 2009; DeMott et al., 2011), and this likely relates to modest variations in the total length of exposure to the ice-coated growth region of the CFDC due to manually controlling the water volume pumped into the CFDC chamber during wall icing cycles. In practice, when sampling atmospheric particle distributions, we have observed droplet breakthrough to occur at between 106.5 and $108.5 \% \mathrm{RH}_{\mathrm{w}}$ for the CSU CFDC. This is in part due to sampling particles with sizes up to the $50 \%$ cut-point limit of 1.5 to $2.4 \mu \mathrm{m}$ inlet impactors used operationally in different studies to assure that larger particles are not falsely counted as ice crystals. Droplet breakthrough $\mathrm{RH}_{\mathrm{W}}$ also depends on processing temperature, as discussed by Richardson (2009).

Due to this upper $\mathrm{RH}_{\mathrm{W}}$ limitation for processing, a reference or normalizing $\mathrm{RH}_{\mathrm{W}}$ condition for assembling common CFDC laboratory and field data on immersion freezing was selected as $105 \%$ for the central lamina condition, or $5 \%$ supersaturation with respect to water. An additional consid- eration in selecting this value is that $\mathrm{RH}_{\mathrm{w}}$ uncertainty, as estimated and extrapolated from Richardson (2009), is $\pm 1.6,2$, and $2.4 \%$ at $-20,-25$, and $-30{ }^{\circ} \mathrm{C}$, respectively (Hiranuma et al., 2014). Thus, a processing $\mathrm{RH}_{\mathrm{w}}$ of $105 \%$ assures that particles are exposed to a minimum $\mathrm{RH}_{\mathrm{W}}$ of $\sim 102 \%$ at the central lamina position, a value that should favor droplet activation even for wettable particles at sizes exceeding the lower limit $(>0.1 \mu \mathrm{m})$ that typifies most INPs on the basis of theoretical (Marcolli et al., 2007) and observational (DeMott et al., 2010) studies.

Figure 2 also demonstrates a common feature noted in earlier studies of polydisperse populations of both mineral dust (DeMott et al., 2011) and biomass burning aerosols (Petters et al., 2009) acting as INPs, which is the asymptotic rise in INP active fraction when $\mathrm{RH}_{\mathrm{W}}$ exceeds $100 \%$, up to the upper limit for droplet breakthrough. This result suggests that unresolved factors are limiting the full expression/observation of immersion freezing nucleation in the CFDC until relatively high water supersaturation. Extended discussion of factors influencing this feature that require further research is given in Appendix B, but we here follow Petters et al. (2009) in interpreting that the INP active fraction at high $\mathrm{RH}_{\mathrm{W}}$, prior to droplet breakthrough, reflects the maximum INP activity achievable at a given CFDC processing temperature for which all particles have been activated into cloud droplets and diluted sufficiently to promote immersion freezing. Additional experimental support for the fact that nearly complete $\mathrm{CCN}$ activation and growth of mineral dust particles occurs in the CSU CFDC at $\mathrm{RH}_{\mathrm{w}}$ between 105 and about $110 \% \mathrm{RH}_{\mathrm{W}}$ is given in Appendix B, Fig. B2. We may contrast our assumptions and approach in this regard to that of Welti et al. (2014), who used separate experiments to define immersion freezing fractions and then applied calculation and subtraction methods to interpret and attribute additional INP fractions freezing as contributions from a condensation freezing process at $\mathrm{RH}_{\mathrm{W}}>100 \%$.

\subsection{AIDA cloud chamber and data analysis}

The AIDA cloud simulation chamber is a large vessel with a volume of $84 \mathrm{~m}^{3}$ that can be sealed and evacuated to simulate cloud parcel expansion. It has been used extensively for ice nucleation studies and specifically for investigations and parameterization of immersion freezing nucleation (Niemand et al., 2012). Detailed descriptions of the device and instrumentation are given in Möhler et al. (2006) and Wagner et al. (2006). Preparation of the chamber for cloud expansions involves flushing with clean synthetic air to reduce particle concentrations to below $0.1 \mathrm{~cm}^{-3}$ and using initial expansions to create a thin ice layer on the chamber walls so that the relative humidity is close to ice saturation at the start temperature for cloud expansions. Initial temperature is set by cooling the insulated box enclosure that surrounds the stainless steel chamber. Locking and evacuating the chamber leads to adiabatic temperature reduction within the cham- 
ber and cloud formation occurs once the humidity exceeds $100 \%$ with respect to water. Temperature uncertainty is $0.2 \mathrm{~K}$ and uncertainty in relative humidity with respect to ice is approximately $5 \%$. The time length of cloud expansions is ultimately limited by heat transfer into the cloud volume and sedimentation of larger cloud particles.

Aerosols tested as ice nuclei are typically first generated into the $4 \mathrm{~m}^{3}$ aerosol chamber before being drawn into the AIDA chamber (Kanji et al., 2011). Dust samples were produced using an RBG-1000 rotating brush disperser (Palas $\mathrm{GmbH}$ ), while Snomax ${ }^{\mathrm{TM}}$ bacteria were generated using spray atomization and mixing with dry air. Ambient air can also be drawn directly into the AIDA chamber. Total particle number concentration is measured continuously using a condensation particle counter (CPC3010, TSI Inc.) and size distributions are determined pre-expansion using a scanning mobility particle sizer (SMPS, TSI Inc.) and an aerodynamic particle sizer (APS, TSI Inc.). Cloud droplet and ice crystal counting and sizing are achieved with two Welas optical particle counters (Palas $\mathrm{GmbH}$ ) as described by Benz et al. (2005).

Analysis of AIDA cloud expansion data in immersion freezing experiments follows Niemand et al. (2012), as shown in Fig. 3. As for the CFDC, we interpret AIDA activation of natural mineral dust INPs as occurring in a deterministic manner, although differences between the two techniques could also reflect longer activation times at the modest cooling rates $\left(\sim 1 \mathrm{~K} \mathrm{~min}^{-1}\right.$ after cloud forms) in AIDA expansions. Figure 3 shows an expansion that followed the CFDC sampling shown in Fig. 2. Full activation of aerosol into cloud droplets is achieved in AIDA ( $\pm 30 \%$ maximum deviation, as noted by Niemand et al., 2012) and ice active fraction of aerosol frozen exceeds 0.001 below about $250 \mathrm{~K}$ and 0.01 by $247 \mathrm{~K}, 4 \mathrm{~min}$ after cloud formation. Note that we utilize AIDA data only up to the point that ice number concentrations are still increasing, and so terminate analyses of ice active fraction beyond this point. Ice crystals much larger than $100 \mu \mathrm{m}$ can exist after this time, so that sedimentation begins to become significant in the chamber, and this is a useful diagnostic for terminating the attribution of INP number concentrations and active fraction to instantaneous temperature in the chamber.

\subsection{Parameterization approach}

The D10 parameterization of a "global" type of INP collected from multiple locations took the form

$n_{\mathrm{INP}}\left(T_{\mathrm{k}}\right)=a\left(273.16-T_{\mathrm{k}}\right)^{b}\left(n_{\mathrm{a}>0.5 \mu \mathrm{m}}\right)^{\left(c\left(273.16-T_{\mathrm{k}}\right)+d\right)}$,

where $a=0.0000594, b=3.33, c=0.0264, d=0.0033, T_{\mathrm{k}}$ is cloud temperature in kelvin, $n_{\mathrm{a}>0.5 \mu \mathrm{m}}$ is the number concentration $\left(\mathrm{std} \mathrm{cm}^{-3}\right)$ of aerosol particles with diameters larger than $0.5 \mu \mathrm{m}$, and $n_{\mathrm{INP}}\left(T_{\mathrm{k}}\right)$ is ice nucleating particle number concentration $\left(\operatorname{std~}^{-1}\right)$ at $T_{\mathrm{k}}$.

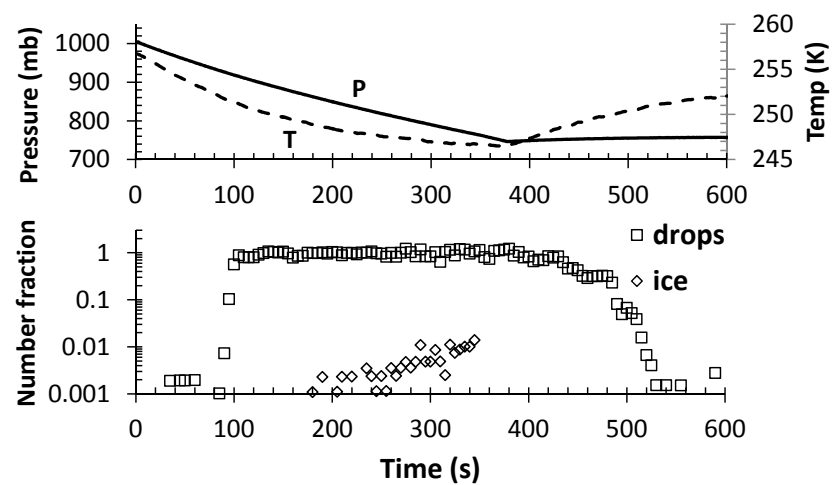

Figure 3. Temperature, pressure, and the number fractions of particles in droplets and ice crystals for the ICIS 2007 AIDA cloud expansion experiment \#22 using Saharan dust aerosols. The data $(0.2 \mathrm{~Hz}$ as plotted) indicate the complete activation of particles to cloud droplets and minor fractions of these particles activating as INPs as the chamber temperature cools. Calculation of ice active fraction is suspended at the point of strong ice crystal sedimentation after $350 \mathrm{~s}$.

Tobo et al. (2013) proposed a modified version of Eq. (1) to more generally describe the size and temperature dependence of various composition-specific types of INPs, which we modify slightly to

$$
\begin{aligned}
& n_{\mathrm{INP}}\left(T_{\mathrm{k}}\right)=(\mathrm{cf})\left(n_{\mathrm{a}>0.5 \mu \mathrm{m}}\right)^{\left(\alpha\left(273.16-T_{\mathrm{k}}\right)+\beta\right)} \\
& \quad \exp \left(\gamma\left(273.16-T_{\mathrm{k}}\right)+\delta\right) .
\end{aligned}
$$

The calibration factor (cf) factor was not included in Tobo et al. (2013), by default being set to 1 . The other equation coefficients could encapsulate this constant, but we will use it as a means to segregate instrumental calibration factors when assessing maximum immersion freezing concentrations or active fractions of mineral dust particles, as will be further addressed in this paper. As for Eq. (1), the units of concentration in this equation are at standard temperature and pressure conditions.

Less accurate predictability might be expected in relating $n_{\mathrm{INP}}\left(T_{\mathrm{k}}\right)$ to larger aerosol particle concentrations rather than to aerosol surface area, which is expected to be a more natural unifying factor as regards quantifying the ice nucleation ability of specific types of INPs (Niemand et al., 2012; Murray et al., 2012; Knopf and Alpert, 2013). We evaluate this point using atmospheric data, as discussed in the next section.

We apply Eq. (2) to describe INP number concentrations for a specific category taken to represent all mineral dusts, a simplification we support with the existing data. Again, we will also follow the approach of Petters et al. (2009) to quantify the maximum immersion freezing activity of laboratorygenerated mineral dust particles using CFDC data, in consideration of instrumental and microphysical factors that lead to an $\mathrm{RH}_{\mathrm{w}}$ dependence of INP number concentrations above water saturation in CFDC-style instruments. This exercise 
defines a single cf value. The derived cf value is applied to CFDC data collected on aerosols present prior to cloudforming expansions in the AIDA chamber in order to test consistency with ice fractions formed in the laboratory supercooled clouds. We also compare Eq. (2) with the active site density (INPs per surface area) parameterization for mineral dust INPs of Niemand et al. (2012) for atmospheric measurements in a Saharan dust layer. This case is introduced in the next section.

\subsection{Case study and other field data}

A case study from the ICE-T experiment was selected for use in comparing the developed parameterization to the surface active site density parameterization of dust INP number concentration (Niemand et al., 2012). The NSF/NCAR C130 aircraft flew an instrument package including meteorological and state parameter measurements, aerosol and cloud microphysical wing-mounted probes, aerosol- and gas-phase sampling systems that used inlets to the cabin (this included the CFDC), and the Wyoming cloud radar (WCR) and lidar (WCL) instruments (Wang et al., 2012). The forward-facing isokinetic aerosol inlet used is the same as described by Eidhammer et al. (2010). Concentrated African dust particle layers were sampled on only a few days during the month-long ICE-T study. The case selected, from 4 July 2011 (called RF02 in the ICE-T data archive at NCAR), included perhaps the most prominent elevated African dust layer that was sampled during the study. This case was quite similar to the African dust layer case documented near Florida by DeMott et al. (2003), but the CFDC processing conditions in the present case were selective for heterogeneous immersion freezing, as already discussed. A vertical profile during descent through the dust layer and into the marine boundary layer (MBL) is shown in Fig. 4. The dust layer is clearly distinguished by the higher aerosol number concentrations and surface areas at sizes above $0.5 \mu \mathrm{m}$ measured by the wingmounted FSSP-300 (Forward Scattering Spectrometer Probe - 300) at between 1300 and $4000 \mathrm{~m}$ altitude. This aerosol signature is not associated with clouds, as evidenced by the lower relative humidity in this altitude range. The composition of this elevated aerosol layer is inferred to be dominated by mineral dusts due to the prediction of transported dust in the region by global aerosol forecast models (not shown) and by the higher values of lidar linear depolarization ratio (LDR) measured by the WCL in the layer above about $1300 \mathrm{~m}$, as shown in Fig. 4. LDR, which is the ratio of perpendicular backscatter intensities to parallel backscatter intensities with respect to the transmitter polarization axis, is an excellent diagnostic for mineral dust (Sassen et al., 2003; Wang et al., 2009). Figure 4 thus demonstrates a clear distinction between the mineral dust layer and the MBL below this level. This transition in aerosol characteristics provides a stringent and informative case for testing parameterizations of mineral dust INPs.

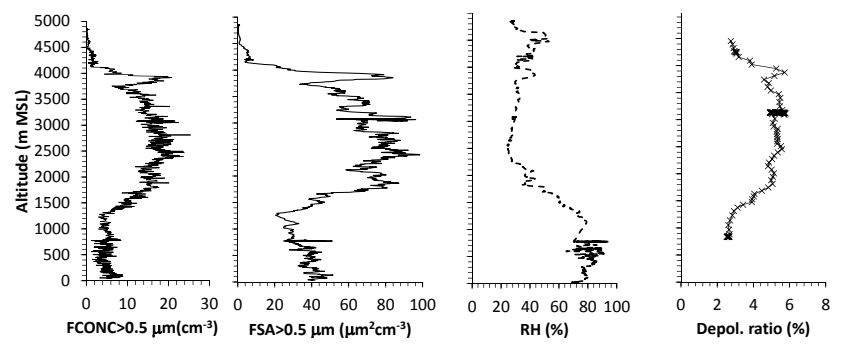

Figure 4. Vertical profiles during descent sounding by C-130 aircraft on 4 July 2011 during the ICE-T study. Panels from left to right, respectively, are FSSP-300 ambient particle concentrations in clear air at optical diameters larger than $0.5 \mu \mathrm{m}$, FSSP-300 surface area in the same size range, relative humidity, and lidar linear depolarization ratio.

Other brief entries into the dust layers during ICE-T RF02 (4 July 2011), and PACDEX G-V flight data from RF12 (22 May 2007) and RF14 (24 May 2007) obtained while tracking a cross-Pacific dust plume described by Stith et al. (2009), were used in the compilation of CFDC data for parameterization development. Lidar data were not available during PACDEX, and so identification of dust layers was primarily by the presence of larger particles at higher altitudes in predicted plume regions (Stith et al., 2009).

\section{Results}

\subsection{Parameterization of CFDC INP data}

CFDC measurements of $n_{\mathrm{INP}}\left(T_{\mathrm{k}}\right)$ processed at $105 \% \mathrm{RH}_{\mathrm{w}}$ vs. $n_{\mathrm{a}>0.5 \mu \mathrm{m}}$, measured with the CFDC optical particle counter, are shown in Fig. 5 at nominal $5 \mathrm{~K}$ temperature intervals. Data collected while sampling particles aerosolized from Asian and Saharan soil sources into the AIDA aerosol chamber are included together in Fig. 5 with field measurements made within Saharan and Asian dust plumes. Laboratory data represent 1 to $3 \mathrm{~min}$ average data, while field data are averaged over 5-30 min periods, as per protocol used by DeMott et al. (2010). Uncertainties represented by error bars on data points are twice the sampling error assuming Poisson arrival statistics for CFDC INP counts. Figure 5 also shows that INP number concentrations increase by approximately a factor of 10 per $5^{\circ} \mathrm{C}$ temperature interval at any $n_{\mathrm{a}>0.5 \mu \mathrm{m}}$. While differences of a factor of 2 to 3 are seen amongst different lab and field aerosols for processing at one temperature, these results suggest that it is possible to approximately unify the different data sets using Eq. (2). For example, plotted as dashed lines in Fig. 5 is Eq. (2) with $\mathrm{cf}$ $=1, \alpha=0, \beta=1.25, \gamma=0.46$, and $\delta=-11.6$, considering all data taken as one sample. As a reminder, cf is taken as 1 in this case because these are CFDC data collected specifically at the reference $\mathrm{RH}_{\mathrm{w}}$ value of $105 \%$. Comparison of predicted vs. observed INP number concentrations for the en- 


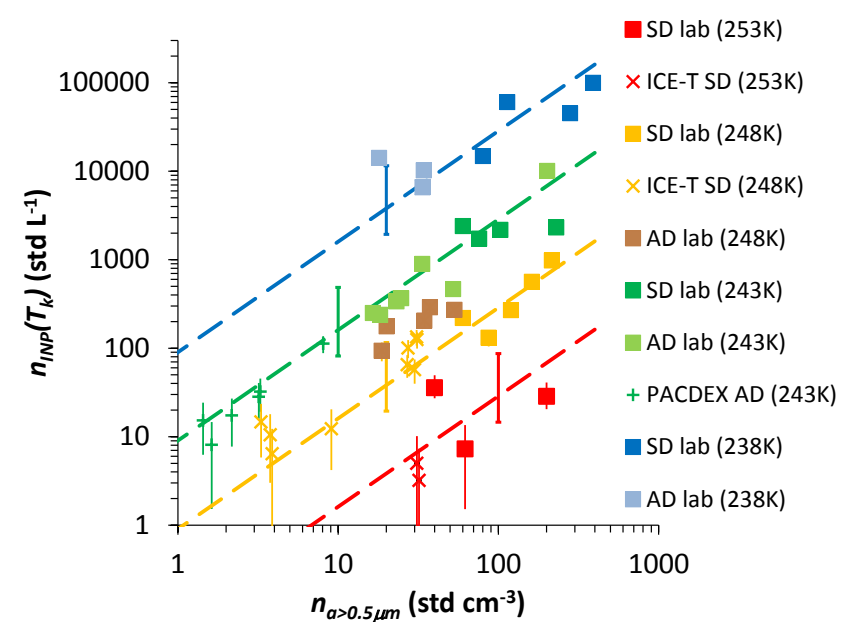

Figure 5. Relations between CFDC INP number concentrations measured at a nominal value of $105 \% \mathrm{RH}_{\mathrm{W}}$ and $n_{\mathrm{a}>0.5 \mu \mathrm{m}}$ in laboratory (lab) and field (PACDEX and ICE-T) measurements of Asian (AD) and Saharan (SD) dust particles at temperatures of approximately 253, 248, 243, and $238 \mathrm{~K}$. Dashed lines are not best fits for each temperature, but are instead determined from the empirical fit given by Eq. (2) ( $\mathrm{cf}=1, \alpha=0, \beta=1.25, \gamma=0.46$, and $\delta=-11.6$ ). Uncertainties in observational data, given as twice the Poisson sampling error for the time-integrated samples, are shown by vertical error bars on data points. Note that at higher $n_{\mathrm{INP}}$ these error bars are not visible beyond the plotted point size. Representative measures of standard error in the predicted lines (see Fig. 6) are shown by capped error bars.

tire data set are shown in Fig. 6. The $r^{2}$ of the fit is 0.94, and the corresponding standard errors (a factor of $\sim 2$ ) and $95 \%$ confidence intervals (a factor of $\sim 4$ ) are also shown. Representative standard errors at specific temperatures are also mapped onto the predicted lines in Fig. 5. These analyses suggests that, to first order, the INP activity of these dusts that surely contain gross mineralogical differences can nevertheless be quantitatively described by the same relation for application in a relatively simple form in numerical models.

This parameterization for mineral dust particles is compared to the D10 parameterization at $-30^{\circ} \mathrm{C}(243.2 \mathrm{~K})$ and $-20^{\circ} \mathrm{C}(253.2 \mathrm{~K})$ in Fig. 7. At lower temperatures and higher dust number concentrations, the D10 parameterization may strongly underestimate INP number concentrations. However, the parameterizations are less distinguishable at certain warmer temperatures and at lower values of $n_{\mathrm{a}>0.5 \mu \mathrm{m}}$. Both parameterizations remain weakly constrained at temperatures warmer than $-20^{\circ} \mathrm{C}$, where much additional ambient and laboratory data are needed. The parameterization developed herein is strictly valid where data were available, between 238 and $252 \mathrm{~K}$, and use to warmer temperatures represents pure extrapolation.

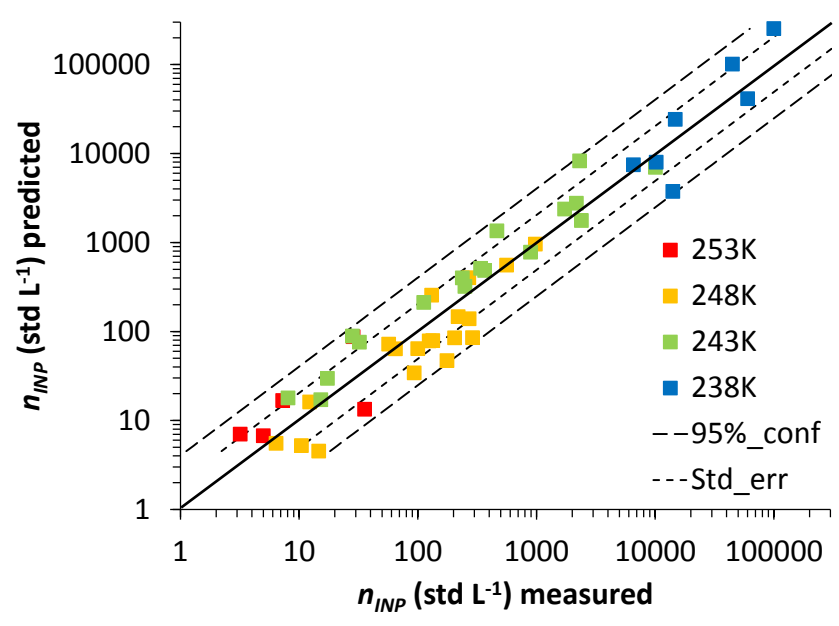

Figure 6. Prediction of Eq. 2 ( $\mathrm{cf}=1, \alpha=0, \beta=1.25, \gamma=0.46$, and $\delta=-11.6$ ), plotted vs. raw field and laboratory data collected at $105 \% \mathrm{RH}_{\mathrm{W}}$ (Fig. 5), with lines added around the $1: 1$ line (solid) to indicate standard error (short-dashed lines) and $95 \%$ confidence intervals (long-dashed lines).

\subsection{Maximum active freezing fractions - derivation of calibration factor (cf) and comparison to AIDA cloud expansions}

We utilized a number of additional CFDC experiments from the ACI-03 campaign at a variety of processing temperatures, while sampling of aerosols from the aerosol storage vessel, to perform a comparison/calibration of the INP number concentration at maximum $\mathrm{RH}_{\mathrm{w}}$ values measured to $n_{\mathrm{INP}}\left(T_{\mathrm{k}}\right)$ at $105 \% \mathrm{RH}_{\mathrm{w}}$. These results are shown in Fig. 8. The regression line in Fig. 8 is drawn for the range of atmospherically realistic INP number concentrations, primarily including data only to as low as $-30^{\circ} \mathrm{C}$, which are the conditions also used by Niemand et al. (2012) to determine their surface-area-based parameterization. The calibration factor for maximum active fraction is approximately 3 , and we suggest this value as the cf prefactor in Eq. (2) for applying the parameterization to atmospheric data. We repeat the caveat that the influences on the maximum INP number concentration values measured by the CSU CFDC are not clearly resolved, and could mask a warm temperature bias to the fraction of particles active at the steady-state processing temperature set in the CFDC (see Appendix B). For this reason, comparison was sought vs. ice formation data from AIDA cloud expansion experiments, considered as ground truth for clouds.

For comparison of CFDC INP data with AIDA chamber experiment data, experiments were utilized for which direct sampling of aerosol conditioned in the AIDA chamber was done with the CFDC prior to first expansion cloud formation in ACI-03 and ICIS studies. Additionally, we considered only experiments for which the CFDC and AIDA cloud temperatures were within $1^{\circ} \mathrm{C}$ of each other, or for which the 

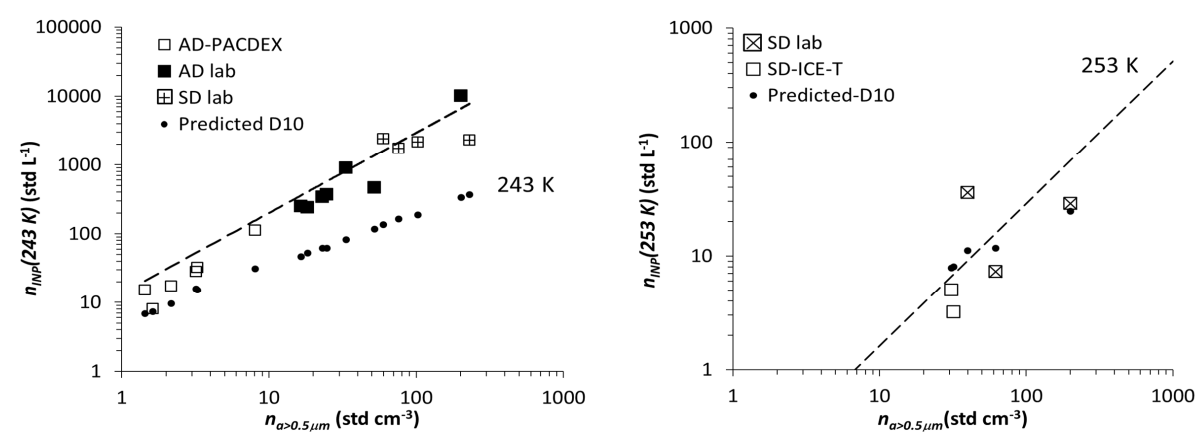

Figure 7. As in Fig. 5, but comparing raw (Fig. 5) and predicted ( $\mathrm{cf}=1$ ) results to the D10 parameterization (calculated for the same data) at nominal temperatures of 243 and $253 \mathrm{~K}$. Note that the D10 parameterization does not produce a straight line in the panel figures due to the variation of temperature within $1 \mathrm{~K}$ that was allowed in the analysis.

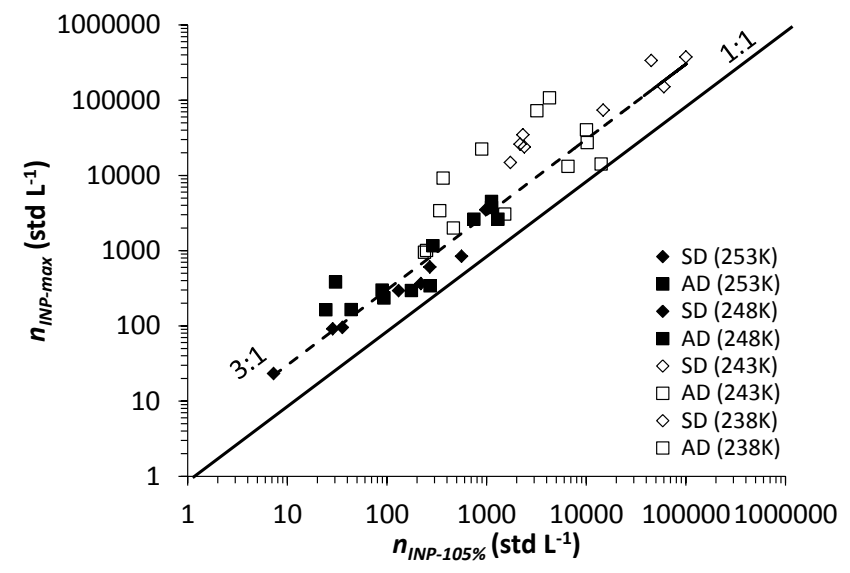

Figure 8. CFDC INP number concentration at peak $\mathrm{RH}_{\mathrm{w}}$ values (preceding droplet breakthrough) in comparison to $n_{\mathrm{INP}}$ measured at $105 \% \mathrm{RH}_{\mathrm{w}}$. A range of temperatures from approximately 253 to $238 \mathrm{~K}$ are represented, as shown. The dashed line expresses $\mathrm{cf}$ $=3$ as a uniform correction on INP number concentration for this selection of data.

CFDC processed at two temperatures to allow linear interpolations of INP numbers and active fractions for comparison. These restrictions limited the number of such comparisons available from sampling of INPs in past studies.

There were a total of eight experiments, listed in Table 1, for which a direct comparison of CFDC maximum INP number concentration at a given temperature sampled from AIDA pre-expansion, and equivalent immersion freezing INP concentration and active fraction from the subsequent first AIDA expansions were available. Table 1 also notes the aerosol concentration larger than $0.5 \mu \mathrm{m}$, as required for parameterization following Eq. (2), and total aerosol surface area as required by the parameterization of Niemand et al. (2012). The INP types represented in this comparison are Saharan (SD) and Asian dust (AD2), Canary Island dust (CID), ambient particles (Amb), and sprayed/dried Snomax ${ }^{\mathrm{TM}}$ bacterial particle suspensions, as described by Niemand et al. (2012)

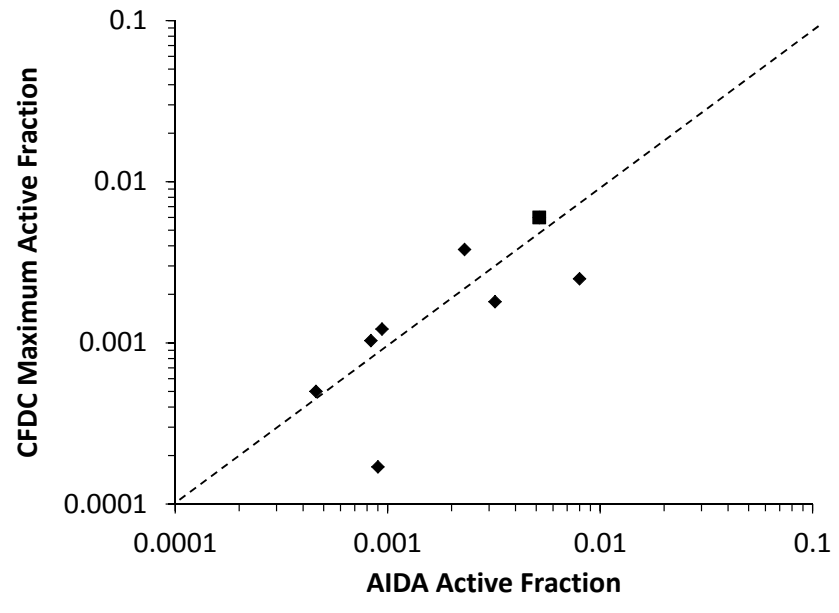

Figure 9. Comparison of CFDC maximum INP active fraction and AIDA cloud expansions active fractions for common experiments when the CFDC sampled from the AIDA chamber prior to first expansion. The square point is for an experiment using Snomax ${ }^{\mathrm{TM}}$ particles.

and Kanji et al. (2011). In some cases, the mineral dusts were coated by exposure to secondary organic aerosol formation, noted as "cSOA" in Table 1. Comparison of active fractions from the two instruments is shown in Fig. 9. General agreement is found between the measurement methods, with a bias toward higher INP concentrations in AIDA for this small sample of experiments.

In Fig. 10, the mineral dust parameterization with $\mathrm{cf}=3$ in Eq. (2) is compared to the D10 parameterization to highlight the steeper activity dependence of mineral dust particles compared to all types of INPs sampled to formulate D10. One might wonder whether the cf factor should be applied to the D10 measurements as well, but further measurements will be needed to determine if corrections are valid for all the types of natural ice nuclei represented in the D10 measurements at different temperatures. This is especially highlighted in Fig. 10 by the fact that mineral dusts do not explain 
Table 1. Equivalent experiment comparisons between CFDC and AIDA.

\begin{tabular}{lllrrrrr}
\hline Project & Experiment & $\begin{array}{l}\text { INP } \\
\text { type }\end{array}$ & $\begin{array}{r}T \\
(\mathrm{~K})\end{array}$ & $\begin{array}{r}\text { AIDA INP } \\
\text { fraction }\end{array}$ & $\begin{array}{r}\text { CFDC INP } \\
\text { fraction }\end{array}$ & $\begin{array}{r}n_{\mathrm{a}>0.5 \mu \mathrm{m}} \\
\left(\mathrm{cm}^{-3}\right)\end{array}$ & $\begin{array}{r}S_{\text {tot }} \\
\left(\mu \mathrm{m}^{2} \mathrm{~cm}^{-3}\right)\end{array}$ \\
\hline ICIS & 23 & CID & 247.9 & 0.0009 & 0.0012 & 36.0 & 61 \\
ICIS & 20 & SD & 249.7 & 0.0023 & 0.0038 & 28.0 & 102 \\
ACI-03 & 43 & Amb & 238.3 & 0.0009 & 0.0002 & 10.1 & 246 \\
ACI-03 & 9 & AD2cSOA & 245.1 & 0.0032 & 0.0018 & 58.0 & 226 \\
ACI-03 & 7 & AD2cSOA & 245.6 & 0.0080 & 0.0025 & 29.0 & 117 \\
ACI-03 & 2 & AD2 & 248.2 & 0.0008 & 0.0010 & 0.8 & 2.3 \\
ACI-03 & 3 & AD2 & 247.2 & 0.0005 & 0.0005 & 0.6 & 3.1 \\
ICIS & 26 & Snomax & 265.2 & 0.0052 & 0.0060 & 88.0 & 1089 \\
\hline
\end{tabular}

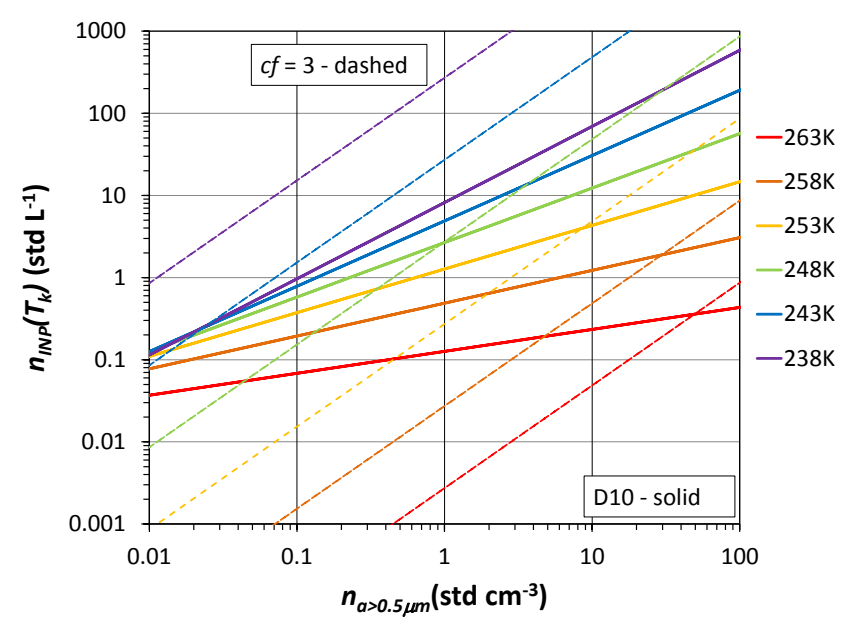

Figure 10. Comparison of ice nucleation parameterization from this study (Eq. 2 with $\mathrm{cf}=3$ ), with the D10 parameterization for calculations in the mixed-phase cloud regime.

the INP activity suggested using the D10 parameterization at temperatures warmer than $253 \mathrm{~K}$, at least for typical atmospheric $n_{\mathrm{a}>0.5 \mu \mathrm{m}}$ of less than a few $\mathrm{cm}^{-3}$. This is the temperature regime that may be dominated by organic ice nucleating particles such as ice nucleating bacteria (Garcia et al., 2012; O'Sullivan et al., 2014). It is also a temperature regime where more data were collected for D10 vs. very little in the present work.

\subsection{Case study intercomparison}

It is clear that the new mineral dust parameterization should reasonably predict the CFDC data observed in the Saharan aerosol layer profile during the RF02 flight in the ICE$\mathrm{T}$ study, since these data were included in the set used for developing the parameterization. Nevertheless, the comparison is useful for evaluating the consistency or differences between different INP parameterizations when applied for ambient aerosol data, including mineral dust particle distributions extending to sizes $>2.5 \mu \mathrm{m}$ that were not sampled into the CFDC. As noted in Fig. 4, Saharan aerosols were focused within a layer overlying the MBL, with total surface areas per unit volume exceeding $8 \times 10^{-11} \mathrm{~m}^{2} \mathrm{~cm}^{-3}$ and number concentrations as high as $30 \mathrm{~cm}^{-3}$ at sizes above $0.5 \mu \mathrm{m}$ as measured by a forward-scattering spectrometer probe (FSSP-300, Droplet Measurement Technologies, Boulder, CO). Such layers were not seen in aerosol vertical profiles or in lidar data on non-dusty days (not shown). INP number concentration data from the descent sounding through this layer is shown in Fig. 11, plotted as $30 \mathrm{~s}$ running average data instead of averages over an integrated period. Appropriate uncertainties are shown for this averaging interval at two representative altitudes and INP number concentrations. As repeat sampling of the layer was originally intended (but was instead terminated by early landing), CFDC sample flow was stopped for a short period during the stepped descent (note data at $\sim 3000$ and $700 \mathrm{~m}$ levels represent additional time spent at those levels) to remove an ice crystal impactor collecting activated particles, and then a period of filtering sample air was performed to quantify and correct for background counts that can potentially be generated through frost particle ejection from surfaces in the chamber (Prenni et al., 2009). This transition interrupted assessment of INP concentration through the depth of the layer, but since aerosol concentrations were continuously sampled by the FSSP-300, the parameterizations could be applied using CFDC sample temperatures during the balance of the descent. FSSP-300 number concentrations of particles at sizes above $0.5 \mu \mathrm{m}$ were used within the mineral dust parameterization, while the FSSP-300 surface area was used within the Niemand et al. (2012) parameterization. For simplification, we apply that parameterization to the integrated aerosol surface area per unit volume $\left(S_{\text {tot }}\right.$ in $\left.\mathrm{m}^{2} \mathrm{~cm}^{-3}\right)$ at sizes above $0.5 \mu \mathrm{m}$ to obtain $n_{\mathrm{INP}}\left(T_{\mathrm{k}}\right)$ in units per ambient liter as

$n_{\mathrm{INP}}\left(T_{\mathrm{k}}\right) \approx 1 \times 10^{-3} S_{\mathrm{tot}} n_{\mathrm{s}}\left(T_{\mathrm{k}}\right)$,

where $n_{\mathrm{S}}\left(T_{\mathrm{k}}\right)\left[\mathrm{m}^{-2}\right]$ is given by Niemand et al. (2012) as

$n_{\mathrm{s}}\left(T_{\mathrm{k}}\right)=\exp \left[-0.517\left(T_{\mathrm{k}}-273.15\right)+8.934\right]$.

The approximation in Eq. (3) bypasses a usual need to bin surface area by particle size and integrate the terms within an 
exponential (cf. Eq. (2) of Niemand et al., 2012). We consider it valid for the case shown in Fig. 11 because the contributions of aerosols larger than $5 \mu \mathrm{m}$ were limited, and because the CFDC temperature used limits the total active fractions of particles in the size range below $5 \mu \mathrm{m}$ to less than about 0.1 , and hence binning surface area is not required for accuracy.

The results shown in Fig. 11 demonstrate several points. First, $n_{\mathrm{INP}}\left(T_{\mathrm{k}}\right)$ as measured by the CFDC while processing at $105 \% \mathrm{RH}_{\mathrm{w}}$ is well reproduced by the new mineral dust parameterization (Eq. 2 with $\mathrm{cf}=1$ ) within the Saharan aerosol layer. This is to be expected on the basis of the parameterization development in Sect. 3.1, where cf $=1$ represents uncorrected data. However, in the MBL, CFDC IN data are already grossly overestimated by the uncorrected mineral dust parameterization ( $\mathrm{cf}=1)$, and even appear overestimated by the global IN parameterization (D10). This result suggests that the aerosol and INPs in the MBL are quite distinct from the Saharan aerosol layer, which has not been well mixed into the MBL at the location of measurements. Within the mineral dust layer, the corrected form of the parameterization using $\mathrm{cf}=3$ is in excellent agreement with the Niemand et al. (2012) parameterization (trace "N12") for this case. While providing confidence that both parameterizations can thus be used to describe atmospheric ice nucleation by mineral dust particles specifically in the temperature ranges for which they were developed, we note that comparison to ice formation in atmospheric clouds has yet to be examined.

\section{Conclusions}

A parameterization based on a combination of laboratory and field data was developed to specifically quantify the immersion freezing numbers of natural mineral dust particles. This parameterization links the prediction of ice nucleating particle number concentrations to particle number concentrations at sizes larger than $0.5 \mu \mathrm{m}$ and to temperature, but is specific to mineral dust compositions. In this manner, the higher efficiency of mineral dust particles in comparison to globalaverage INPs at temperatures colder than $-20^{\circ} \mathrm{C}$ is quantified for use in numerical models. Use of the parameterization to warmer temperatures necessarily entails extrapolation of the present results. Agreement was found between this simplified parameterization and the surface-area-based parameterization of Niemand et al. (2012), developed solely from laboratory data, supporting the atmospheric applicability of laboratory ice nucleation results to the atmosphere. Consequently, our results additionally support the premise of Niemand et al. (2012) that, to a first order, mineral dust particles from locations as separate as the Saharan or Asian regions may be parameterized as a common particle type for numerical modeling purposes. The reason for this result is not entirely clear, given the clear mineralogical differences present in and transported from different desert regions (Murray et al., 2012). Possibly, the relatively high abundance (> $20 \%$

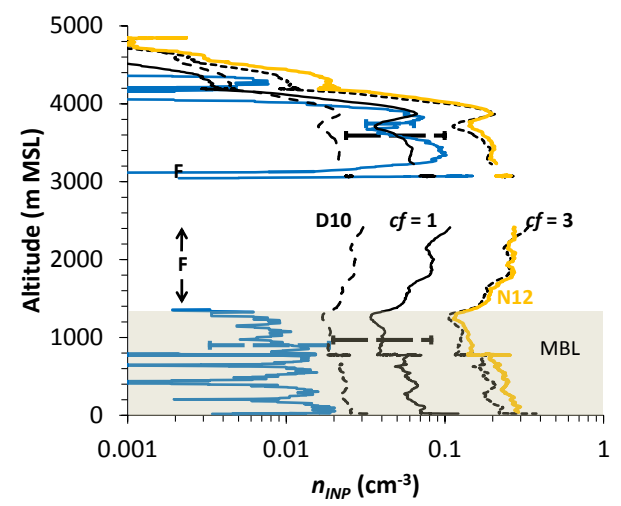

Figure 11. Comparison of ice nucleation data and parameterizations for data collected onboard the NSF/NCAR C-130 aircraft during the ICE-T study descent sounding through a Saharan dust layer shown in Fig. 4. CFDC INP data plotted as a 30 s running average at ambient conditions are given by the blue trace, the D10 parameterization is the long-dash trace, the solid black trace labeled $\mathrm{cf}=1$ is the uncalibrated parameterization derived using Eq. (2) ( $\alpha=0, \beta=1.25$, $\gamma=0.46$, and $\delta=-11.6$ ), and the short-dash trace labeled $\mathrm{cf}=3$ is the calibration-corrected parameterization with the same coefficients, both also corrected from STP (standard temperature and pressure) to ambient INP concentrations. Uncertainties representing twice the Poisson sampling error of the $30 \mathrm{~s}$ running average data are given at two altitudes, and the standard errors of the $\mathrm{cf}=3$ prediction are shown at two nearby altitudes. Plotted for comparison is the parameterization of Niemand et al. (2012), using aerosol surface area and CFDC processing temperature as input. CFDC processing temperature cooled from $248 \mathrm{~K}$ at $5 \mathrm{~km}$ to $246 \mathrm{~K}$ at landing, while CFDC calculated $\mathrm{RH}_{\mathrm{w}}$ at the lamina position was maintained at $105 \pm 0.5 \%$. The shaded region represents the marine boundary layer (MBL). Label F indicates that CFDC sample air was being filtered. The data gap is when CFDC flow was shut off to remove an ice crystal impactor.

by mass) of more highly ice active specific components of dusts, such as feldspars, from both Asian and Saharan regions (Atkinson et al., 2013) drives this result. Nevertheless, it remains to be seen that this conclusion is fully consistent with the unifying role of aerosol concentrations at $>0.5 \mu \mathrm{m}$ or total surface area of mineral dust particles on determining INP number concentrations, since many other mineral components make up the balance of dust particle mass. It remains for additional measurements at different locales to further evaluate this conclusion regarding the relative uniformity of INP properties of mineral dust particles globally or, alternately, to demonstrate the special utility of mineralogicalspecific parameterizations. It is also necessary to point out that we have not herein explicitly considered or evaluated the potential impact of aging processes (e.g., uptake condensedphase material) or cloud processing on the measured or predicted immersion freezing activity. Such impacts may or may not already be present in the field measurements. Some of the laboratory experiments included particle coatings with secondary organic aerosol, which appeared to have no signifi- 
cant impact on immersion freezing (to be elaborated on in a future publication). Additionally, we may note that a number of previous studies suggest little influence of aging on immersion freezing of activated cloud droplets by mineral dusts, unless reactions occur between the condensed species and the mineral surface that impact the efficiency of active sites (Sullivan et al., 2010a, b; Niedermeier et al., 2011a; Reitz et al., 2011).

Our investigations support that a calibration factor on CFDC INP concentrations is needed to account for instrumental factors if the intent is to describe the full expression of condensation/immersion freezing by natural mineral dust particles. The CFDC processing $\mathrm{RH}_{\mathrm{w}}$ value that is required for such full expression may exceed that practically possible for use while measuring ambient aerosol size distributions (e.g., without achieving droplet breakthrough contamination of the ice nucleation signal), so further laboratory studies may be required for specific INP aerosol types. We suggest cf $=3$ for predicting $n_{\mathrm{INP}}\left(T_{\mathrm{k}}\right)$ for immersion freezing by natural mineral dusts using Eq. (2), along with the other parameterization coefficients that have been obtained based on sampling at a practical $\mathrm{RH}_{\mathrm{w}}$ of $105 \%$. While the calibration factor did not depend on processing temperature for the mineral dust particles examined, and has been shown to likely be necessary for fully quantifying INPs from biomass burning particles (Petters et al., 2009), cf and the form of this composition-specific parameterization may be specific to the type of INP. For example, Snomax ${ }^{\mathrm{TM}}$ INPs are fully activated in a CFDC by the point of water saturation at all temperatures below about $-7^{\circ} \mathrm{C}$ (see, for example, DeMott et al., 2011), and so no further activation occurs in the supersaturated regime. A data point for such an experiment is shown in Fig. 9, and consequently is a positive outlier of CFDC/AIDA active fraction after application of $\mathrm{cf}=3$. Nevertheless, these results have implications for the design and operation of any CFDC-type ice nucleation instrument, suggesting careful characterization of ice nucleation response to $\mathrm{RH}_{\mathrm{w}}$ for any particular device and different INP types that compose natural populations. In particular, scanning up to and beyond the $\mathrm{RH}_{\mathrm{w}}$ for droplet breakthrough to establish $\mathrm{CCN}$ activation (e.g., Fig. B2) is recommended. This will more clearly define the upper $\mathrm{RH}_{\mathrm{w}}$ limit for assessing ice active fraction vs. temperature uniformly for any INP type being tested and CFDC instrument type being used.
Use of Eq. (2) to describe condensation/immersion freezing nucleation will depend on accurate prediction of where dust particles are present and where they are not, as the gross over-prediction of INPs for the tropical MBL aerosols shown in Fig. 11 demonstrates. Finally, in applying the parameterization in cloud models, consideration may need to be given to $\mathrm{CCN}$ activation properties (i.e., particles must be in droplets) and loss of INPs to wet scavenging that occurs prior to cloud parcels reaching freezing temperatures. A first application of the new parameterization in a prognostic ice nucleation scheme within regional model simulations has been published by Fan et al. (2014). 
Appendix A: A brief discussion of deterministic vs. stochastic analyses and parameterization

The approach in this paper follows the deterministic (or singular) interpretation of immersion freezing data, which approximates immersion freezing as temperature-dependent only and does not quantify time-dependent ice nucleation behavior. This is in contrast to a purely stochastic model or to multi-component stochastic models designed to quantify the time-dependent characteristics of INPs, as summarized, for example, in Niedermeier et al. (2011b), Murray et al. (2012), Wright and Petters (2013), Knopf and Alpert (2013), and Vali (2014). In a deterministic approach, one primarily seeks to define the ice nucleation activity spectrum measured during a set instrument time or using a set cooling rate, represented by a relation between INP number concentrations and temperature for a known total number (e.g., DeMott et al., 2010) or surface area (e.g., Niemand et al., 2012; Hoose and Moehler, 2012; Murray et al., 2012) of particles. Wright and Petters (2013) and Vali (2014) discuss the fact that temperature dependence dominates time dependence for most INP types. An expectation of the applicability of the singular approximation for freezing of natural mineral dusts follows Broadley et al. (2012), wherein NX illite is proposed as a surrogate for airborne mineral dust, and such particles show little dependence of ice nucleation rate on cooling rate. Finally, Wright and Petters (2013) specifically conclude that a CFDC should represent INP concentrations active in updrafts, despite the short observational time for detecting INPs. This is because the additional nuclei active over time at any supercooled temperature are typically found to represent those newly active for an additional 1 to $3 \mathrm{~K}$ cooling. This fact may in many cases simplify numerical model prediction of ice formation, as tracking the budget of an INP population undergoing variable nucleation rates can be difficult to implement in a prognostic cloud model. Deterministic interpretation also involves the most straightforward use of data collected by real-time ice nucleation instruments, and future reanalyses for nucleation rates are still possible.
Knopf and Alpert (2013) also quantify the relation of immersion freezing nucleation rate to water activity, and thus that parameterization unifies heterogeneous immersion freezing for both cloud droplets and non-dilute haze particles that may freeze below water saturation at lower temperatures. In a similar manner, Sassen and Dodd (1988) and DeMott et al. $(1997,1998)$ beforehand applied the concept of effective freezing temperature vs. solution melting point depression to adjust deterministically analyzed freezing data for INPs immersed in dilute droplets to conditions of more concentrated solution droplets. Thus, deterministic models may presumably be formulated to account for the now-recognized water activity dependence of freezing as well. Nevertheless, as already mentioned, this paper focuses on the first-order data needed: the ice nucleation activity temperature spectrum for INPs within pure water droplets. 


\section{Appendix B: Additional discussion of factors affecting INP activation above water saturation in CFDC instruments}

In the analyses presented in this paper, the cf factor in Eq. (2) is defined by assuming that immersion freezing INP number concentrations for mineral dust particles are underestimated at the CFDC reference $\mathrm{RH}_{\mathrm{w}}$ value of $105 \%$, in which case a higher $\mathrm{RH}_{\mathrm{w}}$ value is required to fully activate immersion freezing on the entire aerosol distribution. The need to achieve higher $\mathrm{RH}_{\mathrm{w}}$, as shown in Figure 2, likely relates to both microphysical and instrumental factors that play interwoven roles, with consequent implications for operating CFDC instruments and interpreting their data (DeMott et al., 2011). While this discussion is generally applicable to all CFDC-type instruments, it is specific to the configuration of the CSU CFDC, and results will be different for other similar instruments.

First, if the CFDC exposed all particles to the same conditions for the same amount of time, independent of $\mathrm{RH}_{\mathrm{w}}$, then we should expect a nearly delta-function response of INP number fraction to $\mathrm{RH}_{\mathrm{w}}$ ensuing around the $\mathrm{RH}_{\mathrm{w}}$ values that characterize $\mathrm{CCN}$ activation. For mineral dust particles, hygroscopicity is thought to be low (Koehler et al., 2009a; Herich et al., 2009), but may be mitigated by adsorption activation (Kumar et al., 2009), such that a range of critical supersaturations from a few tenths of a percent to perhaps $1-2 \%$ for smaller particles could be imagined as an inherent kinetic delay for condensation/immersion freezing in the CFDC. There may be kinetic factors as well related to diluting any condensed material away from ice active sites on mineral particle surfaces.

However, in addition to activation effects, the CFDC method neither assures equal exposure of $\mathrm{RH}_{\mathrm{w}}$ nor equal time of immersion of potential INPs in cloud particles at varied $\mathrm{RH}_{\mathrm{w}}$. Again, Fig. 1 shows the dynamic changes in temperature and $\mathrm{SS}_{\mathrm{w}}$ that occur prior to a short period of nearly steady-state conditions that characterize CFDC-type instruments. It is also apparent from Fig. 1 that, for a steady flow rate, the time of existence of droplets exceeding a certain size, e.g., $1 \mu \mathrm{m}$, increases with $\mathrm{RH}_{\mathrm{w}}$. Dynamic consideration given to altering flow rate would be needed in order to maintain the residence time of particles in droplets at the same value for different processing $\mathrm{RH}_{\mathrm{w}}$. The discussion given in Sect. 2.1 was simplified to focus on the central conditions of the CFDC aerosol lamina. However, $\mathrm{RH}_{\mathrm{w}}$ conditions across the aerosol lamina at any one position during transit of particles through the CFDC are also variable. As shown in Fig. B1a, the edge-to-edge $\mathrm{RH}_{\mathrm{w}}$ difference across the aerosol lamina is $2 \%$ for an $\mathrm{RH}_{\mathrm{w}}$ "set point" of $105 \%$ at $-30^{\circ} \mathrm{C}$. That $\mathrm{RH}_{\mathrm{w}}$ difference exists for perfect containment of the aerosol inside the lamina, which may not be achieved operationally, as discussed originally by Rogers (1988). Figure $\mathrm{B} 1 \mathrm{~b}$ revisits this topic, showing recent measurements of the transit of a $1 \mathrm{~s}$ particle pulse through the CFDC. Com- parison of the predicted time of this particle pulse vs. that observed by monitoring the particle number concentration at the CFDC outlet with a condensation particle counter indicate skewing of the timing of the pulse, suggesting a range of pass-through times for particles. These results indicate that although particles are retained mainly within the position of the aerosol stream, some particles likely escape the central lamina to a distance of up to 4 times the lamina breadth. This potential spread in lamina thickness is highlighted by shading in Fig. B1a. Since we do not know the true distribution of particles in this space, we will not pursue a quantitative example here, but it is obvious that a spread of particles, especially toward the cold wall, leads to a wide range of $\mathrm{RH}_{\mathrm{w}}$ exposure of some proportion of particles for a steady-state target $\mathrm{RH}_{\mathrm{w}}$ above water saturation. Only at much higher target supersaturation will the entire lamina reside above water saturation, although this will necessarily increase the breadth of representative temperatures. This could be the most important factor affecting the detection of condensation/immersion freezing nucleation of natural mineral dust particles with a CFDC. Despite these concerns, evidence clearly exists for high CCN active fractions ultimately occurring in the CSU CFDC instrument for $\mathrm{RH}_{\mathrm{w}}$ values close to the values used to define the maximum immersion freezing INP concentrations in these studies. Figure B2 shows two additional experiments from the ICIS-2007 studies where $\mathrm{RH}_{\mathrm{w}}$ was raised to higher values to examine full droplet breakthrough, indicating $\mathrm{CCN}$ fractions up to 0.8. Similar freezing curves occurring for homogeneous freezing of solution droplets have also been previously demonstrated for the CSU CFDC instruments (DeMott et al., 2009; Koehler et al., 2009b; Richardson, 2009; Richardson et al., 2010), indicating no special limitation on freezing high fractions of particles in these instruments. These results support the validity of the assumption that immersion freezing activity is assessed with the CFDC instrument in the present study.

It is also necessary to mention the additional cooling that droplets are exposed to during entry into and persistence through the CFDC evaporation section as a possible positive artifact leading to enhanced ice activation as $\mathrm{RH}_{\mathrm{w}}$ is increased. Evaporation is forced by setting both ice walls to the colder ice wall temperature in the CSU CFDC design. The temperature curve in Fig. 1 shows that droplets do not evaporate until temperature has decreased by $2{ }^{\circ} \mathrm{C}$ for processing conditions of $-30{ }^{\circ} \mathrm{C}$ and $102 \% \mathrm{RH}_{\mathrm{w}}$, while at $105 \%$ $\mathrm{RH}_{\mathrm{w}}$ and higher, droplets do not completely evaporate during cooling by an additional $3{ }^{\circ} \mathrm{C}$ before exiting the chamber and entering the optical counter. Above about $105 \% \mathrm{RH}_{\mathrm{w}}$, these droplets may stay dilute, with the consequence that additional freezing could occur for this reason alone. Crystals nucleating in this region will grow only slowly from their original droplet size, typically less than $1 \mu \mathrm{m} \mathrm{s}^{-1}$, due to the lowered ice supersaturation present. Thus, only at the highest $\mathrm{RH}_{\mathrm{w}}$ approaching water droplet breakthrough would lateforming crystals even have the possibility to exceed the ice 

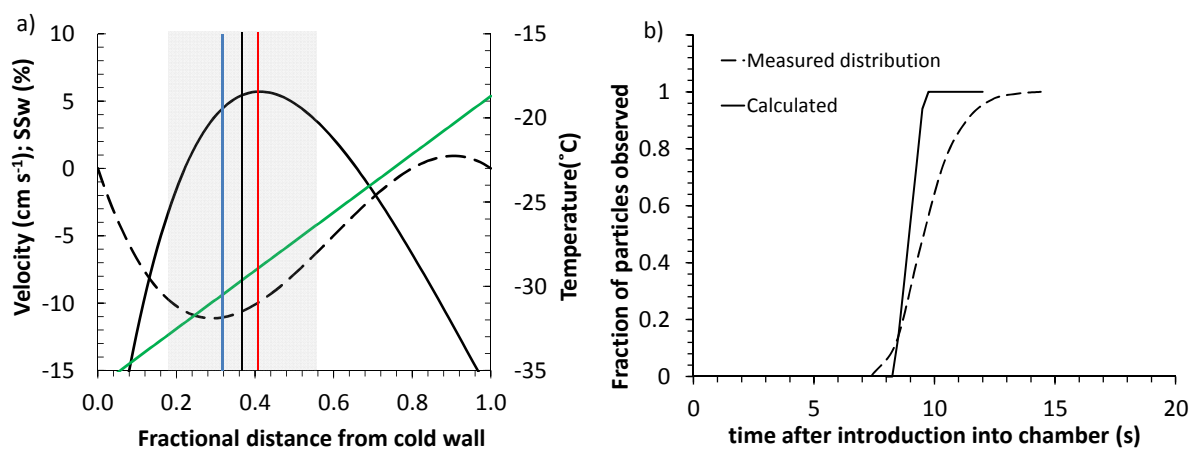

Figure B1. (a) A schematic depiction of a particle beam (shading) spread to a breadth of 4 times the ideal positions of the cold (blue) and warm (red) edges of the aerosol lamina on the basis of transit time measurements of a $1 \mathrm{~s}$ wide aerosol pulse through the CFDC column (b). The transit time measurement for a lamina central temperature of $-30^{\circ} \mathrm{C}$ and $105 \% \mathrm{RH}_{\mathrm{W}}$ is compared to that calculated for a uniform distribution of particles residing fully within the aerosol lamina. Other calculated values in (a) are the temperature profile (green), $\mathrm{SS}_{\mathrm{W}}($ solid black), and downward (negative) air velocity (dashed) in the gap between the CFDC walls.

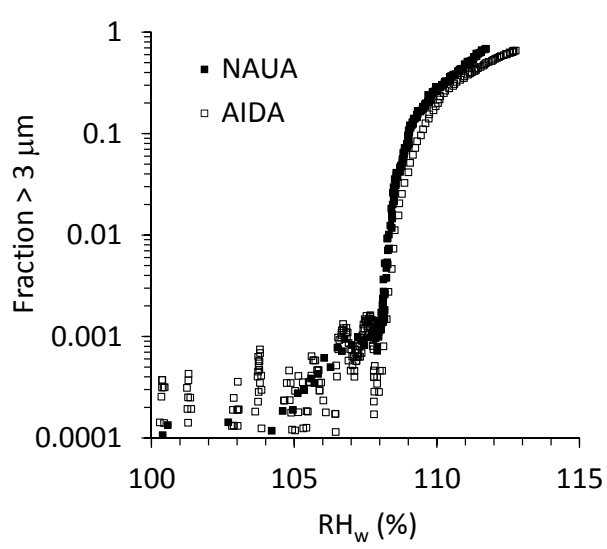

Figure B2. As in Fig. 2, raw $1 \mathrm{~Hz}$ CFDC data from an ICIS2007 experiment on 24 September 2007 showing the fraction of total aerosol concentrations (measured by a condensation particle counter) appearing at optical particle counter sizes above $3 \mu \mathrm{m}$ during $\mathrm{RH}_{\mathrm{W}}$ scanning for two experiments at $-21^{\circ} \mathrm{C}$ when processing particles from a dust sample that had been collected following a dust storm in Israel (Kanji et al., 2011). The data termed NAUA were sampled following dispersion into a $4 \mathrm{~m}^{3}$ aerosol chamber, with concentrations of approximately $5000 \mathrm{~cm}^{-3}$ present at the time of sampling. The data termed AIDA were sampled directly from the AIDA expansion chamber prior to a cloud expansion, when the total particle concentrations were approximately $100 \mathrm{~cm}^{-3}$. Water droplet breakthrough of the CFDC evaporation region occurs at $\sim 108 \%$ in each case, and progressively more activated cloud droplets survive through the evaporation region as $\mathrm{RH}_{\mathrm{W}}$ is increased further.

cut size for detection as IN. Nevertheless, we must necessarily treat this factor as a caveat concerning the corrections to ice active fraction that we propose on the assumption that INP number concentration values measured at high $\mathrm{RH}_{\mathrm{W}}$ are relevant for immersion freezing at the CFDC steady-state temperature.
Time-dependent immersion freezing could be considered as another possible source explaining increasing ice activation vs. $\mathrm{RH}_{\mathrm{w}}$. Inspection of Fig. 1 suggests a tripling of the residence time for droplets larger than $1 \mu \mathrm{m}$ for an $\mathrm{RH}_{w}$ increase from 102 to $109 \%$, whereas Fig. 2 shows an ice active fraction increase of nearly an order of magnitude over this $\mathrm{RH}_{\mathrm{W}}$ range, suggesting that time dependence is not the primary factor at play. Nevertheless, we note again that an analysis of data in terms of nucleation rates has not been performed here, as the target format of the present parameterization is a time-independent form.

These characteristics of continuous flow chambers suggest the need for further investigation, numerically and experimentally, to clarify the specific conditions and residence times attributable to observed ice formation for different types of INP. INP detection may also be influenced by how different CFDC-style devices drive reduction to ice saturation, for example via reduction to the cold wall temperature (Rogers et al., 2001) or to the warm wall temperature (Stetzer et al., 2008). The potential for particles to spread out of the intended focused lamina, and the consequent overall range of processing temperatures and $\mathrm{RH}_{\mathrm{w}}$ represented, probably depends critically on internal design of the aerosol delivery to the center of the processing chamber. In general, these factors reemphasize the point that ice nucleation devices do not yet operate to the potential precision of $\mathrm{CCN}$ devices and therefore require careful consideration when evaluating things like apparent time dependence for ice nucleation or ascribing meaning to the $\mathrm{RH}_{\mathrm{w}}$ dependence of ice nucleation at above water saturation by different INPs. 
Acknowledgements. This work was partially funded by the National Science Foundation under grants ATM-0611936, ATM0841602, AGS-1036028, and AGS-1358495, and the Department of Energy, Office of Science, Office of Biological and Environmental Research program under contract no. SC00002354. J. Snider and Z. Wang acknowledge support through NSF award AGS-1034858. Experiments performed at the Karlsruhe Institute of Technology (KIT) AIDA chamber were supported by the Helmholtz Association through the Virtual Institute on Aerosol-Cloud Interactions (VI-ACI, VH-VI-233) and the research program Atmosphere and Climate (ATMO). P. DeMott also acknowledges KIT for supporting his visit to assist completion of this paper. All processed data are available upon request.

Edited by: H. Su

\section{References}

Atkinson, J. D., Murray, B. J., Woodhouse, M. T., Whale, T. F., Baustian, K. J., Carslaw, K. S., Dobbie, S., O'Sullivan, D., and Malkin, T. L.: The importance of feldspar for ice nucleation by mineral dust in mixed-phase clouds, Nature, 498, 355-358, 2013.

Benz, S., Megahed, K., Möhler, O., Saathoff, H., Wagner, R., and Schurath, U.: T-dependent rate measurements of homogeneous ice nucleation in cloud droplets using a large atmospheric simulation chamber, J. Photochem. Photobiol., 176, 208-217, doi:10.1016/j.jphotochem.2005.08.026, 2005.

Broadley, S. L., Murray, B. J., Herbert, R. J., Atkinson, J. D., Dobbie, S., Malkin, T. L., Condliffe, E., and Neve, L.: Immersion mode heterogeneous ice nucleation by an illite rich powder representative of atmospheric mineral dust, Atmos. Chem. Phys., 12, 287-307, doi:10.5194/acp-12-287-2012, 2012.

DeMott, P.J., Kreidenweis, S. M., and Rogers, D. C.: The susceptibility or ice formation in upper tropospheric clouds to insoluble aerosol components, J. Geophys. Res., 102, 19575-19584, 1997.

DeMott P. J., Rogers, D. C., Kreidenweis, S. M., Chen, Y., Twohy, C. H., Baumgardner, D. Heymsfield, A. J., and Chan., K. R.: The role of heterogeneous freezing nucleation in upper tropospheric clouds: Inferences from SUCCESS, Geophys. Res. Lett., 25, 1387-1390, 1998.

DeMott, P. J., Sassen, K., Poellot, M. Baumgardner, D., Rogers, D. C., Brooks, S., Prenni A. J., and Kreidenweis, S. M.: African dust aerosols as atmospheric ice nuclei, Geophys. Res. Lett., 30, 1732, doi:10.1029/2003GL017410, 2003.

DeMott, P. J., Petters, M. D., Prenni, A. J., Carrico, C. M., Kreidenweis, S. M., Collett Jr., J. L., and Moosmüller, H.: Ice nucleation behavior of biomass combustion particles at cirrus temperatures, J. Geophys. Res., 114, D16205, doi:10.1029/2009JD012036, 2009.

DeMott, P.J., Prenni, A. J., Liu, X., Petters, M. D., Twohy, C. H., Richardson, M. S., Eidhammer, T., Kreidenweis, S. M., and Rogers, D. C.: Predicting global atmospheric ice nuclei distributions and their impacts on climate, P. Natl. Acad. Sci. USA, 107, 11217-11222, 2010.

DeMott, P. J., Möhler, O., Stetzer, O., Vali, G., Levin, Z., Petters, M. D., Murakami, M., Leisner, T., Bundke, U., Klein, H., Kanji, Z., Cotton, R., Jones, H., Benz, S., Brinkmann, M., Rzesanke, D., Saathoff, H., Nicolet, M., Saito, A., Nillius, B., Bingemer,
H., Abbatt, J., Ardon, K., Ganor, E., Georgakopoulos, D. G., and Saunders, C.: Resurgence in ice nucleation research, B. Am. Meteorol. Soc., 92, 1623-1635, 2011.

Eidhammer, T., DeMott, P. J., Prenni, A. J., Petters, M. D., Twohy, C. H., Rogers, D. C., Stith, J., Heymsfield, A., Wang, Z., Haimov, S., French, J., Pratt, K., Prather, K., Murphy, S., Seinfeld, J., Subramanian, R., and Kreidenweis, S. M.: Ice initiation by aerosol particles: Measured and predicted ice nuclei concentrations versus measured ice crystal concentrations in an orographic wave cloud, J. Atmos. Sci., 67, 2417-2436, doi:10.1175/2010JAS3266.1, 2010.

Fan, J., Leung, L. R., DeMott, P. J., Comstock, J. M., Singh, B., Rosenfeld, D., Tomlinson, J. M., White, A., Prather, K. A., Minnis, P., Ayers, J. K., and Min, Q.: Aerosol impacts on California winter clouds and precipitation during CalWater 2011: local pollution versus long-range transported dust, Atmos. Chem. Phys., 14, 81-101, doi:10.5194/acp-14-81-2014, 2014.

Garcia, E., Hill, T. C. J., Prenni, A. J., DeMott, P. J., Franc, G. D., and Kreidenweis, S. M.: Biogenic ice nuclei in boundary layer air over two U.S. High Plains agricultural regions, J. Geophys. Res., 117, D18209, doi:10.1029/2012JD018343, 2012.

Herich, H., Tritscher, T., Wiacek, A., Gysel, M., Weingartner, E., Lohmann, U., Baltensperger, U., and Cziczo, D. J.: Water uptake of clay and desert dust aerosol particles at sub- and supersaturated water vapor conditions, Phys. Chem. Chem. Phys., 11, 7804-7809, 2009.

Heymsfield, A. J. and Willis, P. T.: Cloud conditions favoring secondary ice particle production in tropical maritime convection, J. Atmos. Sci., 71, 4500-4526, doi:10.1175/JAS-D-14-0093.1, 2014.

Hiranuma, N., Augustin-Bauditz, S., Bingemer, H., Budke, C., Curtius, J., Danielczok, A., Diehl, K., Dreischmeier, K., Ebert, M., Frank, F., Hoffmann, N., Kandler, K., Kiselev, A., Koop, T., Leisner, T., Möhler, O., Nillius, B., Peckhaus, A., Rose, D., Weinbruch, S., Wex, H., Boose, Y., DeMott, P. J., Hader, J. D., Hill, T. C. J., Kanji, Z. A., Kulkarni, G., Levin, E. J. T., McCluskey, C. S., Murakami, M., Murray, B. J., Niedermeier, D., Petters, M. D., O’Sullivan, D., Saito, A., Schill, G. P., Tajiri, T., Tolbert, M. A., Welti, A., Whale, T. F., Wright, T. P., and Yamashita, K.: Supplement of: A comprehensive laboratory study on the immersion freezing behavior of illite NX particles: a comparison of seventeen ice nucleation measurement techniques, Atmos. Chem. Phys. Discuss., 14, 22045-22116, doi:10.5194/acpd-14-220452014-supplement, 2014.

Kanji, Z. A., DeMott, P. J., Möhler, O., and Abbatt, J. P. D.: Results from the University of Toronto continuous flow diffusion chamber at ICIS 2007: instrument intercomparison and ice onsets for different aerosol types, Atmos. Chem. Phys., 11, 31-41, doi:10.5194/acp-11-31-2011, 2011.

Knopf, D. A. and Alpert, P. A.: A water activity based model of heterogeneous ice nucleation kinetics for freezing of water and aqueous solution droplets, Faraday Discuss., 165, 513-534, doi:10.1039/C3FD00035D, 2013.

Koehler, K. A., Kreidenweis, S. M., DeMott, P. J., Petters, M. D., Prenni, A. J., and Carrico, C. M.: Hygroscopicity and cloud droplet activation of mineral dust aerosol, Geophys. Res. Lett., 36, L08805, doi:10.1029/2009GL037348, 2009a.

Koehler, K. A., DeMott, P. J., Kreidenweis, S. M., Popovicheva, O. B., Petters, M. D., Carrico, C., Kireeva, E., Khokhlova, T., and 
Shonija, N: Cloud condensation nuclei and ice nucleation activity of hydrophobic and hydrophilic soot particles, Phys. Chem. Chem. Phys., 11, 7906-7920, 2009b.

Kumar, P., Nenes, A., and Sokolik I. N.: Importance of adsorption for $\mathrm{CCN}$ activity and hygroscopic properties of mineral dust aerosol, Geophys. Res. Lett., 36, L24804, doi:10.1029/2009GL040827, 2009.

Marcolli, C., Gedamke, S., Peter, T., and Zobrist, B.: Efficiency of immersion mode ice nucleation on surrogates of mineral dust, Atmos. Chem. Phys., 7, 5081-5091, doi:10.5194/acp-7-50812007, 2007.

Möhler, O., Field, P. R., Connolly, P., Benz, S., Saathoff, H., Schnaiter, M., Wagner, R., Cotton, R., Krämer, M., Mangold, A., and Heymsfield, A. J.: Efficiency of the deposition mode ice nucleation on mineral dust particles, Atmos. Chem. Phys., 6, 30073021, doi:10.5194/acp-6-3007-2006, 2006.

Murray, B. J, O'Sullivan, D., Atkinson, J. D., and Webb, M. E.: Ice nucleation by particles immersed in supercooled cloud droplets, Chem. Soc. Rev., 41, 6519-6554, 2012.

Niedermeier, D., Hartmann, S., Clauss, T., Wex, H., Kiselev, A., Sullivan, R. C., DeMott, P. J., Petters, M. D., Reitz, P., Schneider, J., Mikhailov, E., Sierau, B., Stetzer, O., Reimann, B., Bundke, U., Shaw, R. A., Buchholz, A., Mentel, T. F., and Stratmann, F.: Experimental study of the role of physicochemical surface processing on the IN ability of mineral dust particles, Atmos. Chem. Phys., 11, 11131-11144, doi:10.5194/acp11-11131-2011, 2011a.

Niedermeier, D., Shaw, R. A., Hartmann, S., Wex, H., Clauss, T., Voigtländer, J., and Stratmann, F.: Heterogeneous ice nucleation: exploring the transition from stochastic to singular freezing behavior, Atmos. Chem. Phys., 11, 8767-8775, doi:10.5194/acp11-8767-2011, 2011b.

Niemand, M., Moehler, O., Vogel, B., Vogel, H., Hoose, C., Connolly, P., Klein, H., Bingemer, H., DeMott, P., Skrotzki, J., and Leisner, T.: Parameterization of immersion freezing on mineral dust particles: An application in a regional scale model, J. Atmos. Sci., 69, 3077-3092, 2012.

O'Sullivan, D., Murray, B. J., Malkin, T. L., Whale, T. F., Umo, N. S., Atkinson, J. D., Price, H. C., Baustian, K. J., Browse, J., and Webb, M. E.: Ice nucleation by fertile soil dusts: relative importance of mineral and biogenic components, Atmos. Chem. Phys., 14, 1853-1867, doi:10.5194/acp-14-1853-2014, 2014.

Petters, M. D., Parsons, M. T., Prenni, A. J., DeMott, P. J., Kreidenweis, S. M., Carrico, C. M., Sullivan, A. P., McMeeking, G. R., Levin, E., Wold, C. E., Collett Jr., J. L., and Moosmüller, H.: Ice nuclei emissions from biomass burning. J. Geophys. Res., 114, D07209, doi:10.1029/2008JD011532, 2009.

Phillips, V. T. J., DeMott, P. J., Andronache, C., Pratt, K., Prather, K. A., Subramanian, R., and Twohy, C.: Improvements to an Empirical Parameterization of Heterogeneous Ice Nucleation and its Comparison with Observations, J. Atmos. Sci., 70, 378-409, 2013.

Phillips, V. T. J., DeMott, P. J., and Andronache, C.: An Empirical Parametrisation of Heterogeneous Ice Nucleation for Multiple Chemical Species of Aerosol, J. Atmos. Sci., 65, 2757-2783, 2008.

Prenni, A. J., Petters, M. D., Faulhaber, A., Carrico, C. M., Ziemann, P. J., Kreidenweis, S. M., and DeMott, P. J.: Heterogeneous ice nucleation measurements of secondary organic aerosol generated from ozonolysis of alkenes, Geophys. Res. Lett., 36, L06808, doi:10.1029/2008GL036957, 2009.

Richardson, M. S.: Making Real Time Measurements of Ice Nuclei Concentrations at Upper Tropospheric Temperatures: Extending the Capabilities of the Continuous Flow Diffusion Chamber, Ph.D Dissertation, Colorado State University, 262 pp., 2009.

Richardson, M. S., DeMott, P. J., Kreidenweis, S. M., Petters, M. D., and Carrico, C. M.: Observations of ice nucleation by ambient aerosol in the homogeneous freezing regime, Geophys. Res. Lett., 37, L04806, doi:10.1029/2009GL041912, 2010.

Reitz, P., Spindler, C., Mentel, T. F., Poulain, L., Wex, H., Mildenberger, K., Niedermeier, D., Hartmann, S., Clauss, T., Stratmann, F., Sullivan, R. C., DeMott, P. J., Petters, M. D., Sierau, B., and Schneider, J.: Surface modification of mineral dust particles by sulphuric acid processing: implications for ice nucleation abilities, Atmos. Chem. Phys., 11, 7839-7858, doi:10.5194/acp-117839-2011, 2011.

Rogers, D. C.: Development of a continuous flow thermal gradient diffusion chamber for ice nucleation studies, Atmos. Res., 22 149-181, 1988.

Rogers, D.C., DeMott, P. J., Kreidenweis S. M., and Chen, Y.: A continuous flow diffusion chamber for airborne measurements of ice nuclei, J. Atmos. Ocean. Tech., 18, 725-741, 2001.

Sassen, K., DeMott, P. J., Prospero, J., and Poellot, M. R.: Saharan dust storms and indirect aerosol effects on clouds: CRYSTAL-FACE results, Geophys. Res. Lett., 30, 1633, doi:10.1029/2003GL017371, 2003.

Seifert, P., Ansmann, A., Groß, S., Freudenthaler, V., Heinold, B., Hiebsch, A., Mattis, I., Schmidt, J., Schnell, F., Tesche, M., Wandinger, U., and Wiegner, M.: Ice formation in ashinfluenced clouds after the eruption of the Eyjafjallajökull volcano in April 2010, J. Geophys. Res., 116, D00U04, doi:10.1029/2011JD015702, 2011.

Stetzer, O., Baschek, B., Lüönd, F., and Lohmann, U.: The Zurich Ice Nucleation Chamber (ZINC) - A new instrument to investigate atmospheric ice formation, Aerosol Sci. Tech., 42, 64-74, 2008

Stith, J. L., Ramanathan, V., Cooper, W. A., Roberts, G., DeMott, P. J., Carmichael, G., Hatch, C. D., Adhikary, B., Twohy, C. H., Rogers, D. C., Baumgardner, D., Prenni, A. J., Campos, T., Gao, R. S., Anderson, J., and Feng, Y.: An overview of aircraft observations from the Pacific Dust Experiment campaign. J. Geophys. Res., 114, D05207, doi:10.1029/2008JD010924, 2009.

Sullivan, R. C., Petters, M. D., DeMott, P. J., Kreidenweis, S. M., Wex, H., Niedermeier, D., Hartmann, S., Clauss, T., Stratmann, F., Reitz, P., Schneider, J., and Sierau, B.: Irreversible loss of ice nucleation active sites in mineral dust particles caused by sulphuric acid condensation, Atmos. Chem. Phys., 10, 1147111487, doi:10.5194/acp-10-11471-2010, 2010a.

Sullivan, R. C., Miñambres, L., DeMott, P. J., Prenni, A. J., Carrico, C. M., Levin, E. J. T., and Kreidenweis, S. M.: Chemical processing does not always impair heterogeneous ice nucleation of mineral dust particles, Geophys. Res. Lett., 37, L24805, doi:10.1029/2010GL045540, 2010.

Tobo, Y., Prenni, A. J., DeMott, P. J., Huffman, J. A., McCluskey, C. S., Tian, G., Pöhlker, C., Pöschl, U., and Kreidenweis, S. M.: Biological aerosol particles as a key determinant of ice nuclei populations in a forest ecosystem, J. Geophys. Res.-Atmos., 118, 10100-10110, doi:10.1002/jgrd.50801, 2013. 
Vali, G.: Interpretation of freezing nucleation experiments: singular and stochastic; sites and surfaces, Atmos. Chem. Phys., 14, 5271-5294, doi:10.5194/acp-14-5271-2014, 2014.

Vali, G., Nucleation Terminology, B. Am. Meteorol. Soc., 66, 14261427, 1985.

Wagner, R., Benz, S., Möhler, O., Saathoff, H., and Schurath, U.: Probing ice clouds by broadband mid-infrared extinction spectroscopy: case studies from ice nucleation experiments in the AIDA aerosol and cloud chamber, Atmos. Chem. Phys., 6, 47754800, doi:10.5194/acp-6-4775-2006, 2006.

Wang, Z., Wechsler, P., Kuestner, W., French, J., Rodi, A., Glover, B., Burkhart, M., and Lukens, D., Wyoming Cloud Lidar: instrument description and applications, Opt. Express, 17, 1357613587, 2009.

Wang, Z., French, J., Vali, G., Wechsler, P., Haimov, S., Rodi, A., Deng, M., Leon, D., Snider, J., Peng, L., and Pazmany, A. L.: Single aircraft integration of remote sensing and in situ sampling for the study of cloud microphysics and dynamics, B. Am. Meteorol. Soc., 93, 653-766. doi:10.1175/BAMS-D-11-00044.1, 2012.
Welti, A., Kanji, Z., Luound, F., Stetzer, O., and Lohmann, U.: Exploring the Mechanisms of Ice Nucleation on Kaolinite: From Deposition Nucleation to Condensation Freezing, J. Atmos. Sci., 71, 16-36, 2014.

Wex, H., DeMott, P. J., Tobo, Y., Hartmann, S., Rösch, M., Clauss, T., Tomsche, L., Niedermeier, D., and Stratmann, F.: Kaolinite particles as ice nuclei: learning from the use of different kaolinite samples and different coatings, Atmos. Chem. Phys., 14, 55295546, doi:10.5194/acp-14-5529-2014, 2014.

Wright, T. P. and Petters, M. D.: The role of time in heterogeneous freezing nucleation, J. Geophys. Res.-Atmos., 118, 3731-3743, doi:10.1002/jgrd.50365, 2013. 